\title{
Peranan Psychological Capital terhadap Kesiapan Individu untuk Berubah yang Dimoderatori oleh Persepsi Dukungan Organisasi
}

\author{
Lailatul Munawaroh $^{1}$, \& IJK. Sito Meiyanto ${ }^{2}$ \\ 1,2Fakultas Psikologi Universitas Gadjah Mada
}

\begin{abstract}
The effectiveness of change implementation in an organization depends on the level of individual readiness for change. Low level of individual readiness can cause resistance to change. This study was aimed to test the role of psychological capital (psycap) to individual readiness for change (IRFC) moderated by perceived organizational support (POS). Data were collected using the individual readiness for change scale, the psychological capital scale and the perceived organizational support scale. The subjects were 351 employees of Local Government in Yogyakarta that embrace changing position (inpassing). Moderated regression analysis was used to test the hypothesis. Data analysis showed that both of psycap and POS play role as predictors to IRFC $\left(\mathrm{R}^{2}=0.350 ; \mathrm{p}<0.05\right)$, but POS does not moderates the of effect psycap on IRFC $(\mathrm{F}=2.267 ; \mathrm{p}>0.05)$. This research underlines the importance of resilience as psycap's dimension to increase the individual readiness for change in an organization.
\end{abstract}

Keywords: individual readiness for change; perceived organizational support; psychological capital

\begin{abstract}
Abstrak. Efektivitas intervensi perubahan dalam organisasi dipengaruhi oleh tingkat kesiapan berubah individunya. Penelitian ini bertujuan untuk menguji peran psychological capital terhadap kesiapan individu untuk berubah, dengan persepsi dukungan organisasi sebagai moderator. Metode pengambilan data dilakukan melalui survei dengan menyebarkan skala kesiapan individu untuk berubah, skala psychological capital, dan skala persepsi dukungan organisasi. Subjek penelitian ini adalah 351 pegawai yang tersebar di instansi Pemerintah Daerah DIY yang akan menghadapi perubahan (inpassing) jabatan. Analisis data dilakukan dengan moderated regression analysis. Hasil analisis menunjukkan bahwa psychological capital dan persepsi dukungan organisasi secara bersama-sama memiliki peranan dalam memprediksi kesiapan individu untuk berubah $\left(\mathrm{R}^{2}=0.350\right.$; $\mathrm{p}<0.05)$, namun persepsi dukungan organisasi tidak terbukti memoderasi peranan psychological capital dengan kesiapan individu untuk berubah $(\mathrm{F}=2.267 ; \mathrm{p}>0.05)$. Penelitian ini meneguhkan pentingnya peranan resiliensi sebagai salah satu dimensi psychological capital dalam meningkatkan kesiapan berubah individu dalam organisasi.
\end{abstract}

Kata kunci: kesiapan individu untuk berubah; persepsi dukungan organisasi; psychological capital

\footnotetext{
${ }^{1}$ Korespondensi mengenai artikel ini dapat melalui: lailatul.munawaroh@ugm.ac.id, ${ }^{2}$ smeiyanto@ugm.ac.id 
Kesiapan berubah pada individu dapat membawa berbagai manfaat bagi implementasi perubahan organisasi. Kesiapan berubah yang sudah terbentuk sebelum implementasi perubahan membawa efek positif terhadap kepuasan pegawai terhadap akurasi sistem, kemudahan penggunaan, termasuk pada tahap setelah implementasi (Jones, Jimmieson, \& Griffiths, 2005). Adanya kesiapan berubah pada individu juga terbukti dapat mengurangi penolakan perubahan secara signifikan (Ming-chu \& Meng-hsiu, 2015). Dalam jangka panjang, efektivitas intervensi terhadap suatu organisasi hanya akan dapat diraih oleh organisasi yang anggotanya memiliki kesiapan berubah (Madsen, 2003).

Rendahnya level kesiapan individu seperti juga pengabaian terhadap peranan individu dalam proses perubahan merupakan faktor utama yang menjadi penyebab kegagalan implementasi perubahan (Armenakis, Harris, \& Mossholder, 1993). Kesiapan berubah yang rendah akan membuat pegawai memandang perubahan sebagai sebuah hal yang tidak diinginkan dan perlu dihindari, bahkan menolak untuk berpartisipasi dalam proses perencanaan pelaksanaan perubahan (Shea, Jacobs, Esserman, Bruce, \& Weiner, 2014). Pendapat ini juga diperkuat oleh hasil penelitian Ming-chu dan Meng-hsiu (2015) yang menemukan korelasi negatif yang signifikan antara kesiapan berubah dengan penolakan terhadap perubahan. Dalam arti lain, rendahnya kesiapan berubah memiliki peranan terhadap munculnya penolakan terhadap perubahan.

Mengacu pada hal tersebut, organisasi perlu memastikan bahwa setiap individu memiliki kebutuhan dan kesiapan untuk berubah, dan sebagai langkah awal adalah melalui penilaian kesiapan berubah (Armenakis et al., 1993). Pemimpin organisasi, dalam hal ini perlu untuk menilai kesiapan perubahan sebelum mereka memperkenalkan perubahan itu sendiri, agar mereka mampu mengidentifikasi kesenjangan antara inisiatif mengenai perubahan yang mereka ajukan dengan harapan yang dimiliki pegawai (Holt, Armenakis, Feild, \& Harris, 2007). Hasil penilaian ini diharapkan menjadi panduan bagi organisasi untuk menentukan cara dan langkah terbaik dalam menerapkan perubahan.

Salah satu faktor yang dapat memengaruhi kesiapan individu untuk berubah adalah psychological capital. Penelitian yang dilakukan oleh Ming-chu dan Meng-hsiu (2015) terhadap 288 pegawai industri elektronik di Taiwan menunjukkan bahwa psychological capital dapat membantu pegawai untuk lebih memiliki kesiapan berubah. Hasil penelitian tersebut juga didukung oleh penelitian yang dilakukan oleh Lizar, Mangundjaya, dan Rachmawan (2015) yang menemukan bahwa psychological capital memiliki peranan positif terhadap kesiapan untuk berubah. Senada dengan hasil penelitian sebelumnya, Wang (2015) dari hasil penelitiannya juga menemukan adanya hubungan positif dari psychological capital terhadap perilaku mendukung perubahan.

Psychological capital terdiri dari beberapa komponen yang dapat membantu pegawai untuk melalui proses perubahan yang terjadi di organisasinya. Komponen pertama dari psychological capital yaitu efikasi diri, yang diartikan sebagai keyakinan terhadap kemampuan diri dalam berupaya menghadapi tugas-tugas yang menantang. Keyakinan ini sangat diperlukan bagi pegawai dalam menghadapi perubahan seperti pada masa reeingineering (Armenakis et al., 1993). 
Komponen selanjutnya dari psychological capital adalah optimisme dan harapan (hope). Kedua komponen ini membuat seorang pegawai memiliki keyakinan kuat akan kesuksesan yang dapat diraih apabila perubahan diterapkan, serta tidak mudah menyerah dalam mencapai tujuan. Komponen terakhir dari psychological capital adalah resiliensi, yaitu kemampuan untuk bangkit dari keterpurukan. Resiliensi personal, dari hasil penelitian yang dilakukan Wanberg dan Banas (2000), ditemukan memiliki keterkaitan dengan penerimaan yang lebih tinggi terhadap perubahan.

Selain psychological capital, persepsi terhadap dukungan dari organisasi merupakan faktor lain yang dapat memengaruhi kesiapan seseorang untuk berubah. Persepsi dukungan organisasi merupakan keyakinan global karyawan mengenai sejauhmana organisasi peduli terhadap kesejahteraan mereka dan menghargai kontribusi mereka (Eisenberger, Huntington, Hutchison, \& Sowa, 1986). Pembentukan persepsi dukungan organisasi sangat bergantung pada atribusi pegawai mengenai niatan organisasi di balik perlakuan yang mereka dapatkan dari organisasi tersebut, baik yang menguntungkan maupun merugikan (Kurtessis, Eisenberger, Ford, Buffardi, Stewart, \& Adis, 2015).

Rhoades dan Eisenberger (2002), melalui meta analisisnya terhadap lebih dari 70 penelitian menemukan bahwa persepsi dukungan organisasi dari pegawai yang bersifat positif memiliki keterkaitan dengan sikap yang diinginkan dari pegawai seperti kepuasan kerja, dan komitmen organisasi, serta berkurangnya perilaku negatif seperti penolakan perubahan. Ming-chu \& Meng-hsiu (2015) dalam penelitiannya juga menemukan bahwa pegawai yang mempersepsikan adanya dukungan organisasi dan memiliki kecukupan kesiapan berubah akan mampu mengurangi penolakan terhadap perubahan secara signifikan. Jabbarian dan Chegini (2016) juga mengemukakan hasil serupa dengan kedua penelitian sebelumnya. Persepsi dukungan organisasi dalam penelitian ini terbukti menjadi mediator hubungan negatif antara psychological capital dengan penolakan terhadap perubahan.

Persepsi dukungan organisasi juga terbukti memiliki korelasi positif dan signifikan terhadap kepercayaan dan komitmen terhadap organisasi (Shukla \& Rai, 2015). Lebih lanjut, komitmen terhadap organisasi ditemukan menjadi salah satu faktor pembentuk kesiapan berubah (Kwahk \& Lee, 2008). Semakin tinggi dukungan yang diterima dari organisasi, semakin tinggi juga kesiapan pegawai untuk berubah. Melalui iklim organisasi yang mendukung inilah, harapan dan optimisme terhadap organisasi akan dibentuk pegawai. Selain itu, lingkungan yang penuh dukungan juga mampu mengurangi rasa frustasi pegawai akan kesalahan yang dibuatnya, dan mampu untuk resiliensi (Ming-chu \& Meng-hsiu, 2015). Donsu, Hadjam, Hidayat, \& Asdie (2014) melalui penelitiannya juga menunjukkan bahwa dukungan sosial berperan dalam meningkatkan resiliensi seseorang. Baik harapan, optimisme, maupun resiliensi, semuanya dibutuhkan untuk memperkuat kesiapan berubah bagi individu. Penelitian-penelitian tersebut mengarah pada indikasi bahwa persepsi dukungan organisasi mampu berpotensi memperkuat hubungan antara psychological capital dengan kesiapan berubah dengan cara meningkatkan komitmen, serta memberikan lingkungan yang mendukung bagi 
psychological capital untuk dapat lebih berperan terhadap kesiapan berubah.

Zhao dan Gao (2014) menjelaskan bahwa persepsi dukungan organisasi dapat menjadi moderator bagi psychological capital. Penggunaan variabel moderator sendiri, berguna untuk memberikan implikasi konseptual yang lebih bermanfaat dalam mengungkap fenomena hubungan antar variabel (Baron \& Kenny, 1986). Variabel moderator dijelaskan sebagai variabel yang dapat memengaruhi arah dan atau kekuatan hubungan antara variabel independen dan variabel dependen. Bentuk pengaruhnya dapat saja meningkatkan, menurunkan atau merubah hubungan yang ada antara variabel independen dan dependen. Variabel moderator dapat berupa karakteristik individu seperti jenis kelamin, atau konteksual seperti lingkungan keluarga serta dukungan sosial, termasuk dukungan organisasi.

Penelitian ini bertujuan untuk menguji psychological capital terhadap kesiapan individu untuk berubah, dengan dukungan organisasi sebagai moderator. Hipotesis yang dirumuskan dalam penelitian ini adalah peranan psychological capital terhadap kesiapan individu untuk berubah dimoderatori oleh persepsi dukungan organisasi. Peranan psychological capital terhadap kesiapan berubah menjadi lebih tinggi ketika persepsi dukungan organisasi pada kategori tinggi dibanding dengan persepsi dukungan organisasi pada kategori rendah.

\section{Metode}

\section{Subjek}

Dalam penelitian ini, sebanyak 351 pegawai Pemerintah Daerah DIY yang tersebar di 18 instansi induk maupun unit pelaksana teknis. Subjek terdiri dari 210 (59.8\%) laki-laki dan 141 (40.2\%) perempuan, berusia antara 25-55 tahun. Latar belakang pendidikan subjek paling rendah adalah SMA dan jenjang pendidikan tertinggi adalah S2. Pada umumnya, subjek menduduki jabatan sebagai pelaksana atau staff. Masa kerja subjek bervariasi mulai dari minimal 2 tahun hingga di atas 30 tahun. Sebagian besar subjek berada pada golongan III yaitu sebesar 286 orang. Sisanya sebesar 63 orang berada pada golongan II dan 2 orang pada golongan IV.

\section{Instrumen penelitian}

Instrumen penelitian ini menggunakan skala psikologi dan respon jawaban menggunakan model likert dengan 5 respon jawaban. Skala yang digunakan dalam penelitian ini terdiri dari tiga macam. (1) Skala kesiapan individu untuk berubah yang mengacu pada teori Holt et al. (2007) dengan nilai reliabilitas 0.908. (2) Skala psychological capital yang mengacu pada teori Luthans, Avolio, \& Norman (2007) dengan nilai reliabilitas 0.900. (3) Skala persepsi dukungan organisasi yang mengacu pada teori Eisenberger et al. (1986) dengan nilai reliabilitas 0.918.

\section{Analisis data}

Analisis data yang digunakan dalam penelitian ini adalah uji asumsi klasik dan uji hipotesis. Uji asumsi klasik terdiri dari uji normalitas, uji mulitkolinearitas, dan uji linearitas. Uji hipotesis dalam penelitian ini menggunakan moderated regression analysis.

\section{Hasil}

Deskripsi hasil data penelitian dapat dilihat pada Tabel 1. 
Tabel 1

Deskripsi data variabel penelitian

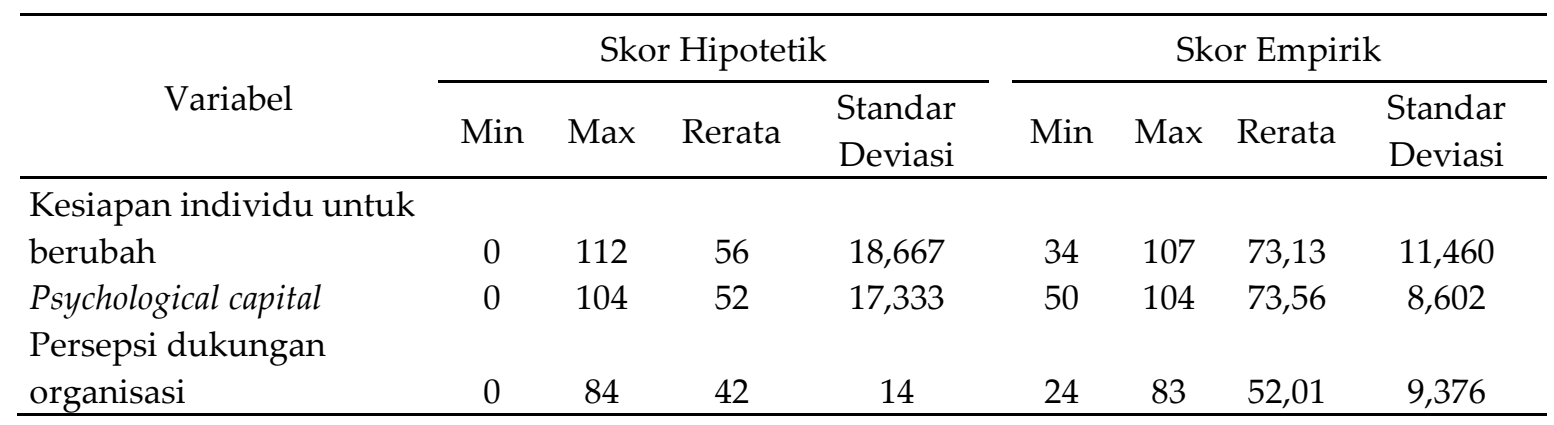

Berdasarkan katagorisasi data hasil penelitian dapat diketahui bahwa pada variabel kesiapan individu untuk berubah, dari 351 orang hanya 1 orang $(0.3 \%)$ berada dalam katagori rendah. 181 (51.6\%) orang berada pada katagori sedang dan 169 (48.1\%) subjek penelitian berada pada katagori tinggi. Pada variabel psychological capital, tidak ada subjek yang berada pada katagori rendah. Sebanyak 103 orang $(29.3 \%)$ berada pada katagori sedang dan 248 orang $(70.7 \%)$ berada pada katagori tinggi. Sedangkan pengkatagorisasian data persepsi dukungan organisasi menunjukkan 4 orang (1.1\%) subjek yang berada pada katagori rendah, 222 orang (63.2\%) dalam katagori sedang, dan 125 orang (35.6\%) berada pada katagori tinggi.

Sebelum melakukan uji hipotesis, terlebih dahulu dilakukan uji asumsi meliputi uji normalitas, uji multikolinearitas, dan uji linearitas. Uji normalitas dengan Kolmogorov-smirnov menunjukkan bahwa distribusi data penelitian bersifat normal dengan nilai sebesar 1.273 dengan $p=0.078 \quad(p>0.05)$. Hasil uji multikolinearitas menunjukkan tidak terjadinya kolinearitas antar variabel prediktor dalam penelitian. Kesimpulan ini didapat dengan melihat nilai tolerance sebesar $0.851(>0.2)$ dan nilai VIF sebesar 1.175 ( $<10)$ pada variabel persepsi dukungan organisasi dan psychological capital. Sedangkan hasil uji linearitas menunjukkan bahwa hubungan antar variabel bersifat linear $\mathrm{F}=188.361$ $(\mathrm{p}<0.01)$ untuk psychological capital, dan 47.397 ( $\mathrm{p}<0.01$ ). Dari keseluruhan hasil uji asumsi klasik, maka model penelitian ini dapat dinyatakan memenuhi persyaratan untuk diuji regresi.

Setelah melakukan uji asumsi, selanjutnya pengujian hipotesis dilakukan melalui uji moderasi dengan Moderated Regression Analysis (MRA). Uji ini menggunakan analisis regresi linear berganda yang dalam persamaan regresinya mengandung unsur interaksi (perkalian dua atau lebih variabel independen) yang disebut variabel produk. Efek moderasi secara statistik ditandai dengan signifikansi peran variabel produk terhadap variabel dependen (Baron \& Kenny, 1986).

Proses pengujian dilakukan melalui regresi berjenjang dengan cara memasukkan prediktor dalam regresi secara bertahap. Karena jumlah prediktor dalam penelitian ini ada tiga, termasuk variabel produk, maka regresi dilakukan dalam tiga tahap. Hasil uji moderasi dapat dilihat pada Tabel 2. 
Tabel 2

Hasil Moderated Regression Analysis

\begin{tabular}{llccc}
\hline Model & Variabel Prediktor & R & SE & F \\
\hline 1 & Psychological capital & 0.34 & 9.32 & $180.37^{* *}$ \\
\hline 2 & Psychological capital , Persepsi Dukungan Organisasi & 0.35 & 9.26 & $5.24^{*}$ \\
\hline 3 & Psychological capital , Persepsi Dukungan Organisasi, Produk & 0.35 & 9.25 & 2.27 \\
\hline$* *\left(\right.$ sig<0.01) ${ }^{*}($ sig<0.05) & & &
\end{tabular}

Pada Tabel 2 terlihat ada tiga jenis model, yaitu model 1 hingga 3 sesuai dengan tahapan prediktor yang dimasukkan pada regresi. Analisis regresi tahap 1 menunjukkan nilai $\mathrm{R}^{2}$ sebesar 0.341 dengan $F$ sebesar $18.370(\mathrm{p}<0.05)$. Dari angka tersebut dapat disimpulkan bahwa psychological capital memberikan sumbangan sebesar $34.1 \%$ dalam memprediksi kesiapan individu untuk berubah secara signifikan. Signifikansi peran prediktor dalam memprediksi variabel terikat diperlukan agar uji moderasi bisa dilakukan (Baron \& Kenny, 1986). Oleh sebab itu tahap pengujian analisis moderator pada penelitian ini dapat dilanjutkan.

Pada tahap kedua, variabel persepsi dukungan organisasi dimasukkan ke dalam analisa regresi. Hasil regresi pada tahap ini menunjukkan bahwa psychological capital dan persepsi dukungan organisasi secara bersama-sama mampu memprediksi kesiapan individu untuk berubah. Hal ini dibuktikan dengan kenaikan sumbangan efektif dari 34.1\% menjadi $35 \%$. Sumbangan ini cukup signifikan yang terlihat dari $F=5.327$ $(\mathrm{p}<0.05)$.
Tahap regresi selanjutnya dilakukan dengan memasukkan variabel produk ke dalam regresi. Variabel produk merupakan variabel yang berasal dari perkalian antara variabel psychological capital dengan variabel persepsi dukungan organisasi. Meskipun hasil analisis regresi pada tahap ini menunjukkan kenaikan nilai sumbangan efektif semua prediktor dari 35\% menjadi 35.5\%, kenaikan ini tidak terbukti secara signifikan. Hal ini terlihat dari nilai $\mathrm{F}=2.267 \quad(\mathrm{p}>0.05) . \quad$ Berdasarkan nilai tersebut dapat ditarik kesimpulan bahwa persepsi dukungan organisasi tidak terbukti menjadi moderator hubungan antara psychological capital dengan kesiapan individu untuk berubah.

Berdasarkan empat tahap regresi yang telah dilakukan maka diperoleh kesimpulan bahwa hipotesis penelitian ini ditolak. Psychological capital dan persepsi dukungan organisasi tidak berperan sebagai moderator terhadap hubungan antara psychological capital dan kesiapan individu untuk berubah. Namun kedua variabel tersebut secara sendiri maupun bersama-sama dapat berperan sebagai prediktor terhadap kesiapan seseorang untuk berubah. 
MUNAWAROH \& MEIYANTO

Persamaan regresi model penelitian

Tabel 3

Hasil Analisis Regresi Variabel Independen terhadap Kesiapan Berubah Individu

\begin{tabular}{llrrr}
\hline & \multicolumn{1}{c}{ Model } & \multicolumn{1}{c}{ Beta } & \multicolumn{1}{c}{ K } & Korelasi orde-nol \\
\hline 1 & (Constant) & 13.159 & $2.970^{* *}$ & \\
& Psychological capital & 0.723 & $11.580^{* *}$ & 0.584 \\
& Persepsi Dukungan Organisasi & 0.131 & $2.288^{*}$ & 0.317 \\
\hline
\end{tabular}

${ }^{*}$ sig $\mathrm{p}<0.01,{ }^{* *}$ sig $\mathrm{p}<0.05$

Dari Tabel 3 didapatkan persamaan regresi sebagai berikut:

$$
Y=13.159+0.723 X 1+0.131 X 2
$$

$Y=$ Kesiapan individu untuk berubah

$\mathrm{X} 1 \quad=$ Psychological capital

X2 = Persepsi dukungan organisasi

Persamaan regresi tersebut menunjukkan bahwa apabila X1 mengalami penambahan 1 poin dengan asumsi $\mathrm{X} 2$ tetap, maka Y akan naik sebesar 0.723. Hal ini menunjukkan bahwa jika psychological capital meningkat, maka kesiapan individu juga akan meningkat. Selain itu, persamaan regresi juga menunjukkan bahwa jika X2 mengalami penambahan 1 poin dengan asumsi $\mathrm{X} 1$ tetap, maka nilai $\mathrm{Y}$ akan naik sebesar 0.131. Hal ini menunjukkan bahwa jika persepsi dukungan organisasi meningkat, maka kesiapan individu untuk berubah juga akan meningkat.

Analisa sumbangan efektif dimensi variabel independen

Uji regresi terhadap setiap dimensi dari psychological capital dilakukan untuk mengetahui dimensi yang memiliki kontribusi terbesar dalam memprediksi kesiapan individu untuk berubah. Hasil uji regresi menunjukkan bahwa dimensi resiliensi memberikan sumbangan positif dan signifikan terhadap kesiapan individu untuk berubah. Nilai sumbangan dimensi resiliensi adalah sebesar $17 \%$ dari total $35 \%$, yang didapat dari perkalian antara nilai beta dan zero-order dimensi tersebut. Hasil uji regresi setiap dimensi psychological capital terhadap kesiapan individu untuk berubah dapat dilihat pada Tabel 4 .

Hasil uji menunjukkan bahwa dimensi optimisme tidak memberikan sumbangan signifikan dalam memprediksi kesiapan individu untuk berubah ( $\mathrm{t}=1.607$, $\mathrm{p}>0.05)$. Dari hasil tersebut, maka hanya ada tiga dimensi dari psychological capital yang memiliki kontribusi dalam memprediksi kesiapan berubah, yaitu efikasi diri, harapan (hope), dan resiliensi.

Hasil uji regresi juga menunjukkan bahwa resiliensi tidak hanya memberikan kontribusi terbesar terhadap kesiapan individu untuk berubah, tetapi resiliensi juga menjadi dimensi yang paling dominan dalam memprediksi kesiapan berubah. Hal ini dibuktikan dengan membandingkan kontribusi dimensi resiliensi (beta=.314) dibandingkan dengan kontribusi keseluruhan dimensi psychological capital terhadap kesiapan berubah $\left(\mathrm{R}^{2}=.34\right)$. Dari perbandingan angka-angka tersebut dapat disimpulkan bahwa kesiapan individu untuk berubah lebih dipengaruhi oleh resiliensi saja. 
Tabel 4.

Tabel hasil uji regresi dimensi Psychological Capital

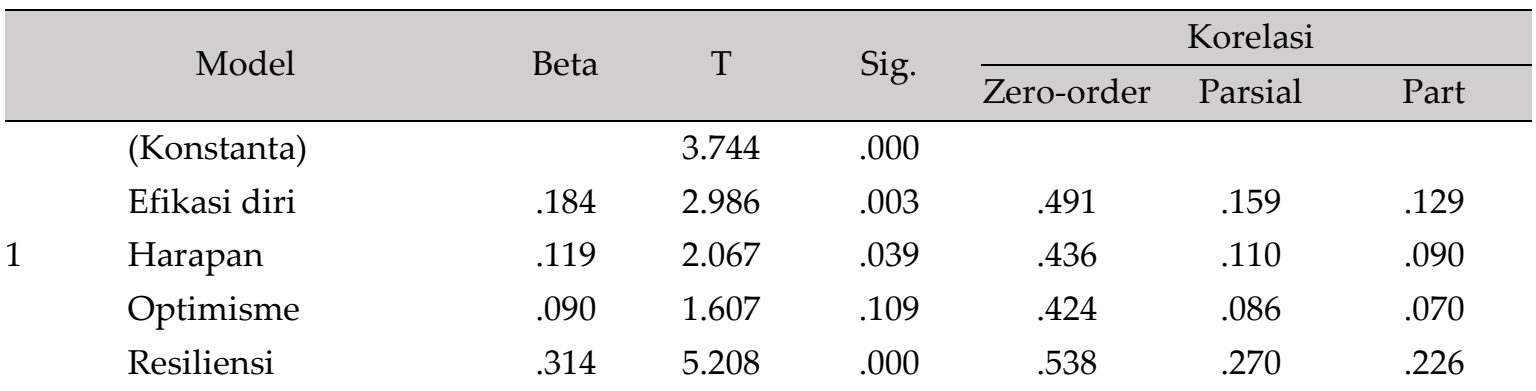

Variabel dependen: Kesiapan Berubah

Pada variabel persepsi dukungan organisasi, hasil uji regresi terhadap aspek-aspek variabel ini menunjukkan bahwa perhatian atas kesejahteraan memberikan sumbangan efektif terbesar dalam memprediksi kesiapan individu untuk berubah (12\%). Sedangkan aspek penghargaan terhadap kontribusi tidak memberikan sumbangan signifikan terhadap kesiapan berubah.

Analisa kesiapan berubah pada individu berdasarkan demografis

Analisa perbedaan kesiapan berubah pada individu berdasarkan faktor demografis dilakukan dengan menggunakan independent sample $t$ test dan anava satu jalur. Hasil analisa menunjukkan tidak adanya perbedaan kesiapan berubah secara signifikan dilihat dari jenis kelamin, usia, masa kerja, golongan, dan jabatan. Faktor demografis yang terbukti memiliki perbedaan kesiapan untuk berubah adalah faktor pendidikan dan instansi tempat bekerja subjek penelitian. Dari hasil post hoc terhadap golongan pendidikan, subjek dengan pendidikan SMA atau diploma memiliki rata-rata kesiapan lebih rendah dibandingkan dengan kelompok subjek berpendidikan S1 maupun S2. Namun post hoc tidak menunjukkan adanya perbedaan kesiapan berubah antara kelompok SMA dan diploma, serta antara kelompok S1 dan S2. Uji post hoc juga membuktikan adanya perbedaan kesiapan secara signifikan dilihat dari instansi tempat bekerja.

\section{Diskusi}

Hasil analisis statistik dalam penelitian ini menunjukkan bahwa psychological capital dan persepsi dukungan organisasi baik secara secara sendiri maupun bersamasama berperan dalam kesiapan individu untuk berubah $\left(\mathrm{R}^{2}=0.350\right.$; $\left.\mathrm{p}<0.05\right)$. Hal ini mengindikasikan bahwa kondisi perkembangan positif seseorang serta keyakinan seorang pegawai mengenai kepedulian organisasi terhadap kesejahteraan berperan terhadap kesiapan individu untuk berubah. Hasil penelitian ini mendukung literatur sebelumya bahwa kesiapan untuk berubah dipengaruhi oleh psychological capital (Lizar et al., 2015; Ming-chu \& Meng-hsiu, 2015)dan persepsi dukungan organisasi (Eby, Adams, Russell, \& Gaby, 2000).

Sebagai kondisi positif yang dimiliki oleh individu, psychological capital memiliki peranan dalam meningkatkan kesiapan berubah melalui beberapa hal. Pertama, dimensi efikasi diri membuat seorang pegawai memiliki kepercayaan diri untuk melakukan tugas-tugas menantang dan melakukan berbagai upaya untuk meraih kesuksesan berbagai tugas, termasuk tugas perubahan. Kedua, dimensi harapan 
(hope) yang membuat pegawai tidak mudah menyerah saat menghadapi rintangan dan bila perlu mengalihkan jalan untuk mencapai tujuan, termasuk tujuan perubahan. Ketiga, dimensi resiliensi membuat seorang pegawai mampu bangkit dari keterpurukan, serta mampu beradaptasi dengan ketugasan baru. Secara keseluruhan, keadaan psychological capital positif yang dimiliki seorang pegawai akan menciptakan suasana hati positif yang pada akhirnya dapat menjadi pemicu munculnya perubahan organisasi yang positif juga (Luthans, Avey, Avolio, Norman, \& Combs, 2006).

Persepsi dukungan organisasi berperan dalam meningkatkan komitmen organisasi, serta memberikan lingkungan yang mendukung bagi psychological capital untuk lebih dapat lebih berperan terhadap kesiapan berubah. Ming-chu dan Menghsiu (2015) menyatakan bahwa lingkungan yang penuh dukungan mampu mengurangi rasa frustasi pegawai terhadap kesalahan yang dibuatnya. Inilah yang membuat pegawai mampu untuk bangkit dari keterpurukan. Selain itu, pegawai yang mempersepsikan secara positif dukungan dari organisasinya membuat pegawai tersebut memiliki harapan dan optimisme terhadap organisasi. Baik harapan, optimisme, maupun resiliensi, semuanya merupakan bagian dari psychological capital yang berperan terhadap kesiapan berubah bagi individu. Sedangkan komitmen terhadap organisasi ditemukan menjadi salah satu faktor pembentuk kesiapan berubah (Kwahk \& Lee, 2008).

Peranan persepsi dukungan organisasi dalam memperkuat psychological capital terhadap kesiapan berubah kemudian diuji pada penelitian ini. Pengujian dilakukan dengan melibatkan persepsi dukungan organisasi sebagai moderator terhadap hubungan antara psychological capital dengan kesiapan individu untuk berubah. Hasil analisis regresi memperlihatkan bahwa persepsi dukungan organisasi tidak berfungsi sebagai moderator bagi hubungan antara psychological capital dengan kesiapan individu untuk berubah ( $F$ change $=2,267 ; p>0,05)$. Hal ini berbeda dengan hasil penelitan (Zhao \& Gao, 2014) yang mengungkapkan bahwa persepsi dukungan organisasi dapat berperan sebagai moderator bagi psychological capital.

Tidak terbuktinya fungsi moderasi pada penelitian ini menunjukkan bahwa psychological capital tidak memiliki interaksi dengan persepsi dukungan organisasi saat memprediksi kesiapan individu untuk berubah. Perbedaan tinggi rendahnya persepsi dukungan organisasi dalam hal ini, tidak memberikan hasil yang berbeda terhadap hubungan antara psychological capital dan kesiapan individu untuk berubah. Seorang pegawai yang memiliki level psychological capital yang tinggi misalnya, yang dalam hal ini ditunjukkan melalui resiliensi yang tinggi, tetap memiliki kesiapan berubah tanpa memperdulikan tinggi rendahnya dukungan organisasi yang dipersepsikannya.

Dimensi resiliensi memungkinkan seseorang untuk bertahan di saat menghadapi situasi yang serba tidak jelas maupun tidak menguntungkan pada saat menghadapi inpassing jabatan. Resiliensi juga memungkinkan individu untuk bangkit dari keterpurukan, sekaligus membuat individu tersebut siap untuk menjalankan ketugasan baru dengan lebih efisien. Individu yang resiliens adalah individu yang memiliki kemampuan adaptasi baik (Lewis, 2011). Kemampuan adaptasi inilah yang dibutuhkan pegawai 
untuk dapat menjalankan tugas-tugas perubahan dengan baik.

Berbagai penjelasan di atas menunjukkan pentingnya resiliensi dalam meningkatkan kesiapan berubah pada seorang pegawai secara langsung, tanpa bergantung pada moderasi dari persepsi dukungan organisasi. Namun tidak menutup kemungkinan, ada hal-hal lain selain persepsi dukungan organisasi yang dapat memengaruhi peranan psychological capital terhadap kesiapan berubah. Memengaruhi pada konteks ini dapat berarti memperkuat, memperlemah, ataupun membalikkan arah hubungan antara psychological capital dan kesiapan berubah. Beberapa variabel lain yang dapat menjadi moderator hubungan antara psychological capital dengan kesiapan berubah adalah kepemimpinan dan komitmen organisasi (Saragih, 2015). Komitmen organisasi sendiri, melalui penelitian Hadiyani dan Zulkarnain (2014), terbukti berperan terhadap kesiapan individu untuk berubah.

Hal lain yang berpotensi memengaruhi kesiapan seseorang untuk inpassing jabatan adalah kebijakan pemerintah yang kerap kali berubah dalam pengelolaan jabatan. Pada awal penerapan UU ASN pada tahun 2014, pembina kepegawaian di tingkat pusat selalu menekankan bahwa jabatan fungsional umum (tenaga administrasi) akan dihilangkan, dan diharapkan tenaga fungsional umum ini akan beralih menjadi fungsional tertentu (profesi tertentu) berdasarkan keahlian yang dimiliki dengan sistem seleksi. Seiring berjalannya waktu, jabatan fungsional umum hanya dihilangkan secara nomenklatur, dan diubah namanya menjadi pelaksana dan berlaku secara nasional (Christanto, 2016). Meskipun program inpassing tetap dilaksanakan, perubahan nomenklatur jabatan fungsional umum menjadi pelaksana dapat diterjemahkan sebagai kurangnya komitmen organisasi dalam melaksanakan inpassing.

Hasil penelitian ini menunjukkan bahwa dimensi dari psychological capital yang paling berperan terhadap kesiapan berubah adalah resiliensi. Sedangkan pada persepsi dukungan organisasi, hal-hal yang berhubungan dengan perhatian terhadap kesejahteraan menjadi hal yang paling berperan terhadap kesiapan individu untuk berubah. Secara keseluruhan, resiliensi pada psychological capital merupakan prediktor yang lebih kuat dibandingkan dengan persepsi dukungan organisasi di dalam peranannya terhadap kesiapan individu untuk berubah.

Beberapa ahli menemukan bahwa resiliensi merupakan kondisi yang dapat dikelola, dikembangkan, dan ditingkatkan dalam kehidupan seseorang (Luthans et al., 2006). Peningkatan resiliensi dapat dilakukan melalui beberapa strategi. Lewis (2011) menjabarkan tiga macam strategi untuk meningkatkan resiliensi, antara lain melalui strategi yang berfokus pada asset, strategi yang berfokus pada resiko, dan strategi yang berfokus pada proses. Salah satu strategi meningkatkan resiliensi yang aplikatif bagi organisasi adalah strategi yang berfokus pada asset. Strategi ini ditempuh dengan meningkatkan kesadaran pegawai akan kekuatan/ asset yang dimiliki melalui proses appreciative inquiry (Lewis, 2011). Melalui kesadaran terhadap asset yang dimiliki, seorang pegawai diharapkan dapat meningkatkan kemampuannya dalam memanfaatkan asset yang dimiliki untuk mendukung implementasi proses perubahan. 


\section{Kesimpulan}

Berdasarkan hasil penelitian ini dapat disimpulkan bahwa kesiapan individu untuk menjalani perubahan jabatan dipengaruhi secara signifikan oleh psychological capital dan persepsi individu terhadap dukungan organisasinya. Setiap peningkatan level psychological capital, yang utamanya ditandai dengan kemampuan beradaptasi dan kemampuan untuk bertahan dan bangkit dari keterpurukan atau yang disebut resiliensi, secara positif juga akan meningkatkan kesiapan pegawai untuk menjalani inpassing. Peningkatan level kesiapan inpassing juga dapat terjadi melalui peningkatan keyakinan pegawai mengenai jaminan kesejahteraan yang diterimanya dari organisasi.

Persepsi individu mengenai dukungan organisasi tidak terbukti memperkuat peranan psychological capital terhadap kesiapan pegawai untuk melaksanakan perubahan jabatan. Namun persepsi dukungan organisasi dan psychological capital secara sendiri maupun bersamasama berperan dalam meningkatkan kesiapan pegawai untuk melaksanakan perubahan jabatan. Dibandingkan persepsi individu terhadap dukungan organisasi, kondisi psychological capital khususnya resiliensi yang dimiliki individu memiliki peranan lebih besar dalam peningkatan kesiapan menjalani perubahan jabatan.

\section{Saran}

Saran untuk peneliti selanjutnya adalah untuk menguji model penelitian ini pada subjek ataupun konteks perubahan yang berbeda, untuk menambah wawasan pengetahuan empiris terkait adanya persamaan atau perbedaan mengenai faktor yang berperan terhadap kesiapan individu untuk berubah. Peneliti selanjutnya juga dapat mengidentifikasi dan menganalisis variabel-variabel lain yang berperan terhadap kesiapan individu untuk berubah yang tidak diteliti dalam penelitian ini.

Mengingat pentingnya peranan psychological capital dalam meningkatkan kesiapan individu untuk berubah, maka organisasi khususnya Pemerintah Daerah DIY perlu mempertahankan dan menyediakan lingkungan kerja yang memungkinkan psychological capital, terutama dimensi resiliensi untuk berkembang. Salah satu cara yang dapat ditempuh adalah dengan meningkatkan kesadaran akan sumberdaya atau potensi yang dimiliki seseorang melalui appreciative inquiry. Hal lain yang perlu mendapatkan perhatian adalah perbedaan rata-rata kesiapan yang sangat signifikan antara berbagai instansi di Pemda DIY. Hal ini menandakan perlunya penelitian lebih dalam untuk menganalisis rendahnya kesiapan berubah pada pegawai di instansi tertentu.

\section{Kepustakaan}

Armenakis, A. A., Harris, S. G., \& Mossholder, K. W. (1993). Creating readiness for organizational change. Human Relations, 46(6), 681-703. doi: 10.1177/001872679304600601

Baron, R. M., \& Kenny, D. A. (1986). The moderator-mediator variable distinction in social psychological research : Conceptual, strategic, and statistical considerations. Journal of Personality and Social Psychology, 51(6), 1173-1182.

Christanto, P. (2016, December 28 ). Mulai Januari 2017 tak lagi jabatan fungsional umum. Retrieved June 20, 2017, from https://korpri.id/berita/1757 mulai-januari-2017-jfu-pns-jadijabatan pelaksana 
Donsu, J. D., Hadjam, N. R., Hidayat, R., \& Asdie, A. H. (2014). Peran faktorfaktor psikologis terhadap depresi pada pasien diabetes mellitus tipe 2 . Jurnal Psikologi, 41(2), 241-249. doi: 10.22146/jpsi.6953

Eby, L. T., Adams, D. M., Russell, J. E. A., \& Gaby, S. H. (2000). Perceptions of organizational readiness for change: factors related to employees' reactions to the implementation of team-based selling. Human Relations, 53(3), 419442. doi: $10.1177 / 0018726700533006$

Eisenberger, R., Huntington, R., Hutchison, S., \& Sowa, D. (1986). Perceived organizational support. Journal of Applied Psychology, 71(3), 500-507. doi: 0021-9010/86/SOO.75

Hadiyani, S., \& Zulkarnain. (2014). Peranan komitmen organisasi dan employee engagement terhadap kesiapan karyawan untuk berubah. Jurnal Psikologi, 41(1), 19-35. doi: 10.22146/jpsi.6955

Holt, D. T., Armenakis, A. A., Feild, H. S., \& Harris, S. G. (2007). Readiness for organizational change: The systematic development of a scale. The Journal of Applied Behavioral Science, 43(2), 232255. doi: 10.1177/0021886306295295

Jabbarian, J., \& Chegini, M. G. (2016). The effect of perceived organizational support on employee resistance to change : A study on guilan municipal staff. Journal of History Culture and Art Research, 5(4), 642-654. doi: 10.7596/taksad.v5i4.627

Jones, R. A., Jimmieson, N. L., \& Griffiths, A. (2005). The impact of organizational culture and reshaping capabilities on change implementation success : The mediating role of readiness for change. Journal of Management Studies, 42(2), 361-386.
Kurtessis, J. N., Eisenberger, R., Ford, M. T., Buffardi, L. C., Stewart, K. A., \& Adis, C. S. (2015). Perceived organizational support : A metaanalytic evaluation of organizational support theory. Journal of Management, $X X(X)$, 1-31. doi: 10.1177/ 0149206315575554

Kwahk, K. Y., \& Lee, J. N. (2008). The role of readiness for change in ERP implementation: Theoretical bases and empirical validation. Information and Management, 45(7), 474-481. doi: 10.1016/j.im.2008.07.002

Lewis, S. (2011). Positive psychology at work: How positive leadership and appreciative inquiry create inspiring organization. Oxford: Willey-Blackwell.

Lizar, A. A., Mangundjaya, W. L. ., \& Rachmawan, A. (2015). The role of psychological capital and psychological empowerment on individual readiness for change. The Journal of Developing Areas, 49(5), 343-352. doi: 10.1353/jda.2015.0063

Luthans, F., Avey, J. B., Avolio, B. J., Norman, S. M., \& Combs, G. M. (2006). Psychological capital development: Toward a micro-intervention. Journal of Organizational Behavior, 27(3), 387393. doi: 10.1002/job.373

Luthans, F., Avolio, B. J., \& Norman, S. M. (2007). Positive psychological capital : Measurement and relationship with performance and satisfaction. Personnel Psychology, 60(3), 541-572.

Madsen, S. R. (2003). Wellness in workplace: Preparing employees for change. Organization Development Journal, 21(1), 46-55.

Ming-chu, Y., \& Meng-hsiu, L. (2015). Unlocking the black box : Exploring the link between perceive organizational support and resistance to 
change. Asia Pacific Management Review, 20(3), 177-183. doi: 10.1016/ j.apmrv.2014.10.003

Rhoades, L., \& Eisenberger, R. (2002). Perceived organizational support : A review of the literature. Journal of Applied Psychology, 87(4), 698-714. doi: 10.1037//0021-9010.87.4.698

Saragih, E. H. (2015). Individual attributes of change readiness: A case study at Indonesia State-owned railway company. Procedia-Social and Behavioral Sciences, 172, 34-41. Retrieved from http://doi.org/http://dx.doi.org/10.1016 /j.sbspro.2015.01.332

Shea, C., Jacobs, S. R., Esserman, D. A., Bruce, K., \& Weiner, B. (2014). Organizational readiness for implementing change: a psychometric assessment of a new measure. Implementation Science, 9(7). doi: 10.1186/ 1748-5908-9-7

Shukla, A., \& Rai, H. (2015). Linking perceived organizational support to organizational trust and commitment: Moderating role of psychological capital. Global Business Review, 16(6), 981-996. doi: 10.1177/ 0972150915597599

Wanberg, C. R., \& Banas, J. T. (2000). Predictors and outcomes of openness to changes in a reorganizing workplace. The Journal of Applied Psychology, 85(1), 132-142. doi: 10.1037/00219010.85.1.132.

Wang, L. (2015). The relationship between employee psychological capital and change-supportive behavior: Mediating effect of cognitive of change. Journal of Social Sciences, 3(April), 125-133. doi: 10.4236/ jss.2015.34015.

Zhao, C., \& Gao, Z. (2014). Why do they leave? The mechanism linking employees' psychological capital to their turnover intention. In J. N. Xu, J.V.A. Cruz-Machado, B. Lev (Ed.), Proceedings of the Eighth international conference on management science and engineering management. 281, 925-936. doi: 10.1007/978-3-642-55122-2_80 